\title{
PROTOTYPICAL MODELS OF THE TERMS INTERACTION IN THE TERMINOLOGICAL NETWORK ${ }^{1}$
}

\author{
Maksim N. Latu \\ Pyatigorsk State University, Pyatigorsk, Russia \\ Olga Yu. Gukosyants \\ Pyatigorsk State University, Pyatigorsk, Russia
}

\begin{abstract}
The research is devoted to the current cross-disciplinary problem of the knowledge organization for information search intellectualization and knowledge extraction acceleration by means of the specialized software the expert system. The paper shows that an effective form of knowledge organization in the expert system is the terminological network of subject domain; the network can be structured on the basis of prototypical semantic models of terms interaction which reflect the relations of the concepts designated by terms. The authors reconstruct the fragment of the terminological network of nanotechnologies with the top-term nanoliquid and present it in the article. While analyzing definitions of the terms included into the network and the fragments of scientific publications with terminological units of the analyzed subject domain, the authors define the following semantic categories: Material, Substance, Natural object, Tool, Characteristic, Process. The paper reveals the prototypical models of the terms interaction reflecting the systemic relations between the term "nanoliquid" and its adjacent terms: generic, partitive, attributive, the relations between targeted object and result, between material and process. The article shows that the term "nanoliquid" is introduced in hierarchical classification of the nanostructured materials and has various semantic relations both with terms of one category and with terms of all other semantic categories.

Key words: term, concept, category, system relation, prototypical model, terminological network, systematicity, the Russian language.

Citation. Latu M.N., Gukosyants O.Yu. Prototypical Models of the Terms Interaction in the Terminological Network. Vestnik Volgogradskogo gosudarstvennogo universiteta. Seriya 2, Yazykoznanie [Science Journal of Volgograd State University. Linguistics], 2019, vol. 18, no. 1, pp. 99-112. (in Russian). DOI: https://doi.org/10.15688/jvolsu2.2019.1.8

\section{ПРОТОТИПИЧНЫЕ МОДЕЛИ ВЗАИМОДЕЙСТВИЯ ТЕРМИНОЕДИНИЦ В ТЕРМИНОЛОГИЧЕСКОЙ СЕТИ ${ }^{1}$}

\author{
Максим Николаевич Лату \\ Пятигорский государственный университет, г. Пятигорск, Россия \\ Ольга Юрьевна Гукосьянц \\ Пятигорский государственный университет, г. Пятигорск, Россия
}

Аннотация. Исследование посвящено актуальной междисциплинарной проблеме организации знаний с целью интеллектуализации информационного поиска и ускорения процесса их извлечения посредством специализированного программного обеспечения - экспертной системы. Показано, что эффективной формой организации знаний в экспертной системе является терминологическая сеть предметной области, структурирование которой может быть осуществлено на основе прототипичных семантических моделей взаимодействия терминов, отражающих отношения обозначаемых ими понятий. В статье представлен фрагмент 
реконструированной авторами терминологической сети предметной области нанотехнологий с терминомвершиной наножидкость. В результате анализа дефиниций терминов, входящих в сеть, и контекстов употребления терминологических единиц этой предметной области в научных публикациях определена их принадлежность к одной из семантических категорий: Материал, Вещество, Естественный объект, Инструмент, Характеристика, Процесс. Выявлены прототипичные модели взаимодействия терминов, эксплицирующие системные связи термина наножидкость (родовидовые, партитивные, атрибутивные, результативные, локации) и их направленность. Показано, что данный термин встроен в иерархическую классификацию наноструктурированных материалов и реализует разнообразные семантические отношения как с терминами внутри одной категории, так и с терминами других семантических категорий.

Ключевые слова: термин, понятие, категория, системные отношения, прототипичная модель, терминологическая сеть, системность, русский язык.

Цитирование. Лату М. Н., Гукосьянц О. Ю. Прототипичные модели взаимодействия терминоединиц в терминологической сети // Вестник Волгоградского государственного университета. Серия 2, Языкознание. 2019. - T. 18, № 1. - C. 99-112. - DOI: https://doi.org/10.15688/jvolsu2.2019.1.8

\section{Введение}

Структурированное представление знаний конкретных предметных областей - это актуальная задача современной науки, решение которой возможно с применением различных подходов и методов (подробнее о некоторых методах изучения и моделирования организации научного знания см.: [Гукосьянц, Лату, 2017]). Основными целями создаваемых исследователями моделей организации научного знания являются интеллектуализация информационного поиска, ускорение процесса извлечения данных, облегчение доступности знаний в целом как для предметного эксперта (эксперта в определенной предметной области, сфере научного знания), так и для рядового пользователя.

Один из видов специализированного программного обеспечения, служащего для представления знаний, - экспертная система. Это «программа для компьютера, которая оперирует со знаниями в определенной предметной области с целью выработки рекомендаций или решения проблем» [Джексон, 2001, с. 12]. «Центральной проблемой создания любой экспертной системы является процесс передачи знаний и опыта решения задач экспертом в компьютерную систему, называемый “приобретением знаний”» [Вассерман, Червинская, 2010, с. 28]. От объема приобретенного знания и истинности закладываемых в систему данных, связей и правил зависит уровень работы системы, выполнение запросов пользователей, предоставление качественных результатов.
Основой создания экспертных систем могут служить терминологические семантические сети, которые представляют собой модели терминосистем, репрезентирующих области научного знания [Faber, León, Prieto, 2009]. Базовыми элементами такой модели являются вершины, выраженные терминами, и дуги, репрезентирующие системные семантические отношения между ними [Мальковский, Соловьев, 2012]. Как было показано в наших предыдущих работах, совокупность терминов определенной области знаний (терминосистема) может быть смоделирована в виде сети с узлами-терминами и дугами-отношениями, демонстрирующими особенности взаимодействия конкретных элементов научного знания и позволяющими установить место термина в терминосистеме относительно других терминологических единиц. При этом вершины классифицируются по категориям, отражающим естественную стратификацию терминов в соответствии с категориями понятий, а системные отношения дифференцируются по типам.

Данные категории обладают высокой степенью абстракции в соответствии со спецификой природы их референтов. Так, к категории Естественный объект относятся термины, референтами которых являются все тела естественного происхождения (наночастицы, мицеллы, РНК, ДНК); к категории Инструмент - термины, референтами которых являются все тела искусственного происхождения (инструменты, орудия, детали, продукты производства и т. д., создаваемые с определенной целью и используемые как средство ее 
достижения: нанопленка, наноигла, нановолокно); к категории Вещество - термины, референтами которых являются субстанции естественного происхождения (муравьиная кислота, полимерный гель); к категории Материал термины, референтами которых являются субстанции искусственного происхождения (графен, наножидкость, наноэмульсия); к категории Характеристика - термины, референтами которых являются свойства (прочность, упругость, проводимость), а к категории Процесс - термины, референтами которых являются действия (гидрирование, азотирование, электрохимическое осаждение). Типы системных отношений терминов отражают характер взаимодействия понятий, например, AКО - системное отношение между гиперонимом и гипонимами; РО - между меронимом и холонимом; At - системное отношение атрибутивности, где один референт выступает признаком другого; ObjR - системное отношение между референтами, которые составляют объект воздействия и полученный результат в рамках одного процесса; Loc между референтами, один из которых - место расположения другого; IOp - между видовыми понятиями, представляющими собой согипонимы, внутренняя форма которых не содержит противопоставления; ISA - системное отношение совпадения или включения во множество (где один из референтов не имеет статуса прямого гиперонима по отношению к другому) и др. (более подробно о категориях и типах системных отношений в терминологической сети см.: [Лату, 2016; Лату, Левит, 2016; Левит, 2017]).

Такой подход в силу системного характера терминологической лексики делает прозрачными процессы накопления и организации знаний [Chernyshenko, Alimuradov, 2013], что особенно значимо для молодых развивающихся областей науки [Razduev, 2018].

Одной из важных задач построения терминологической сети является установление категории для каждого термина, представляющего собой отдельную вершину, и типов связей между терминами системы.

Термин встраивается в систему существующего знания посредством установления системных отношений с другими входящими в нее терминами. Связанные термины и от- ношения между ними, репрезентируясь в научных текстах [Gillam, Tariq, Ahmad, 2006; Malaise, Zweigenbaum, Bachimont, 2004], могут быть выявлены с использованием методов дефиниционного, контекстуального и дистрибутивного анализа. Каждый отдельный термин имеет собственный набор смежных терминов [Steyvers, Tenenbaum, 2005], с которыми он связан системными отношениями определенных типов, что детерминирует специфику его системности. При этом каждый смежный термин также относится к той или иной категории. Термины одной категории часто связаны с терминами только некоторых категорий посредством определенных типов системных отношений. Данный факт позволяет говорить о существовании прототипичных схем (моделей) взаимодействия понятий, которые представляют собой более сложные элементы терминологической сети, комплекс из двух взаимосвязанных категорий [Latu, 2018]. Структура прототипичной модели включает четыре базовых элемента: категорию 1, категорию 2, тип системного отношения и его вектор, показывающий направление данной связи. Так, категория может быть связана с другими одним и тем же типом системных отношений, а две идентичные категории в разных терминологических сетях - разными типами системных отношений [Latu, 2018].

В рамках статьи рассмотрена корреляция термина наножидкость с другими терминологическими единицами сферы нанотехнологии и в ходе анализа системных отношений между терминоединицами выявлены некоторые прототипичные модели их взаимодействий. Материалом исследования послужили дефиниции из терминологических словарей, а также научные публикации из электронных и печатных источников (2009-2017), в которых встречается термин наножидкость. Общий объем выборки составил 215 фрагментов специализированных текстов.

\section{Термин наножидкость как вершина}

\section{модели отношений в терминосистеме}

Системность термина наножидкость представлена в виде схемы фрагмента терминологической сети на рисунке. 


\section{РАЗВИТИЕ И ФУНКШИОНИРОВАНИЕ РУССКОГО ЯЗЫКА}

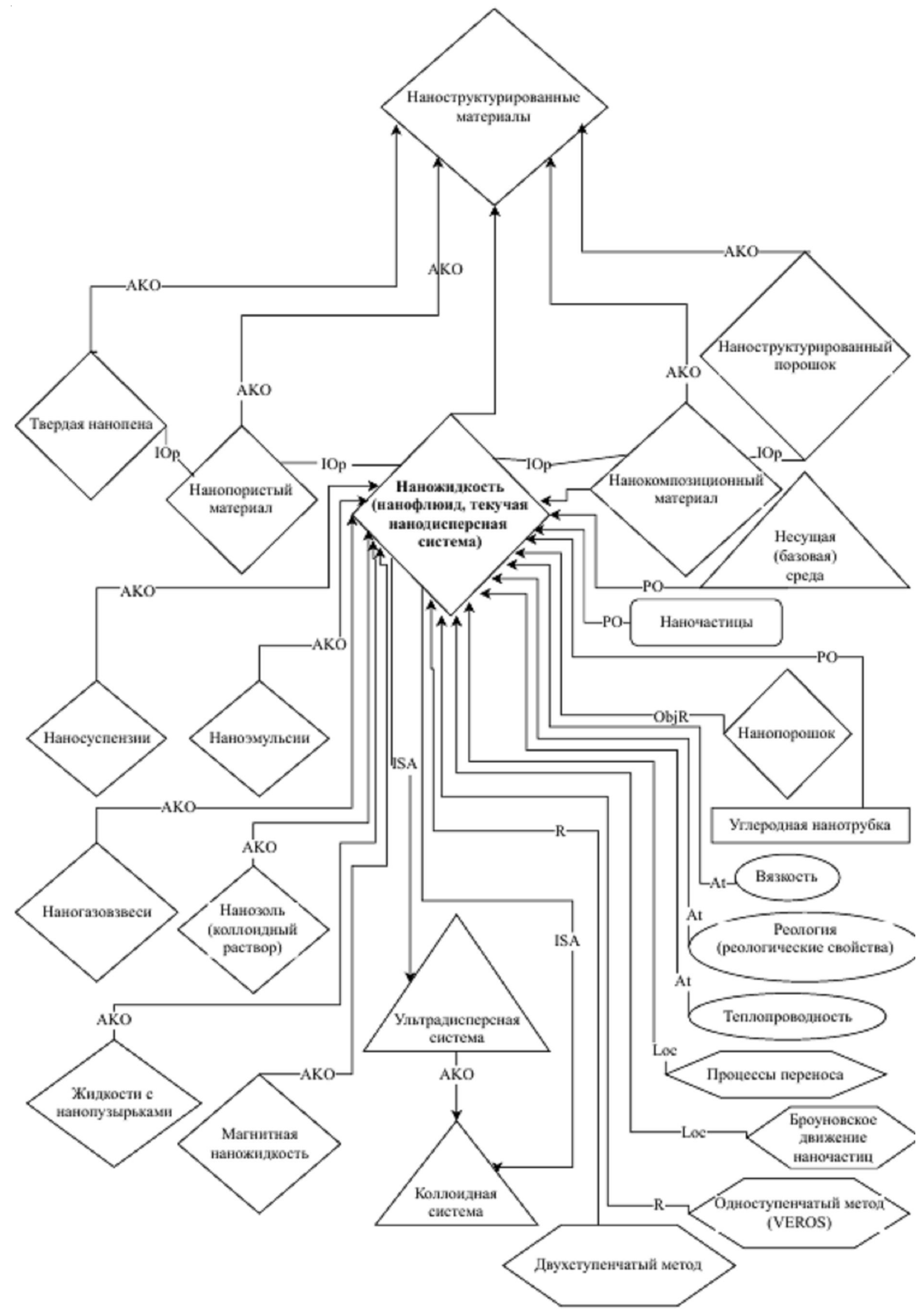

Фрагмент терминологической сети (единицы, системно связанные с термином наножидкость) 
Термин наножидкость входит в категорию Материал, обозначая субстанцию искусственного происхождения:

(1) Когда наножидкости были получены в начале 1990-х, эксперименты показали, что их теплопроводность намного выше ожидаемой (Наножидкости не выдерживают проверки).

(2) Одним из современных направлений развития технологий является создание наножидкостей (НЖ) на основе углеродных наночастиц, в том числе углеродных нанотрубок (УНТ) с регулируемыми параметрами тепло- и массопереноса (Иванов, Ивахнюк).

В некоторых словарных статьях и анализируемых контекстах встречается употребление равнозначного термина-синонима нанофлюид:

(3) Этот нанофлюид (наножидкость) и может использоваться для охлаждения компьютерных серверов (Нанотехнологии могут охлаждать серверные фермы).

(4) Результаты исследований свойств нанофлюидов (жидкостей с добавкой частиц размером от 10 до 100 нм), опубликованные в последние годы, показывают возможность существенного целенаправленного изменения их теплофизических и теплообменных характеристик по сравнению с традиционными рабочими веществами холодильных систем и систем кондиционирования воздуха (Шимчук, Геллер, с. 35).

(5) В качестве перспективного теплоносителя в последнее время обсуждаются нанофлюиды устойчивые суспензии наноразмерных ( 100 нм) частиц металлов и оксидов в базовой жидкости (Рютин, с. 13).

Термину наножидкость синонимично терминологическое сочетание текучая нанодисперсная система. Оно зафиксировано в Межгосударственном стандарте «Нанотехнологии. Часть 4. Материалы наноструктурированные. Термины и определения» (ГОСТ ISO/ TS 80004-4-2016). Согласно стандарту одним из видов наноструктурированных материалов является текучая нанодисперсная система (fluid nanodispertion) - «гетерогенный материал, содержащий нанообъекты или нанофазы, диспергированные в непрерывной жидкой фазе» (c. 4). Данное определение и представленные в ГОСТе подвиды текучей нанодисперсной системы, а именно - наносуспензия, наноэмульсия, наноаэрозоль, жидкая нанопена, которые, как отмечается ниже, являются подвидами наножидкости, свидетельствуют о синонимичности терминов наножидкость и текучая нанодисперсная система.

\section{Прототипичные модели \\ с родовидовыми отношениями между терминами}

Одним из значимых типов связей является системное отношение АКО, посредством которого термин встраивается в иерархическую классификацию, соединяя родовые и видовые понятия, расположенные на разных ее уровнях. Данное отношение частотно. Оно входит в структуру прототипичных моделей, которые раскрывают взаимодействие понятий одной категории. АКО реализуется как отношение гипонима с прямым гиперонимом. Межгосударственный стандарт «Нанотехнологии. Часть 4. Материалы наноструктурированные. Термины и определения» устанавливает «пять видов наноструктурированных материалов: наноструктурированный порошок, нанокомпозиционный материал, твердая нанопена, нанопористый материал, текучая нанодисперсная система» (с. 4). Следовательно, ближайшим родовым термином для термина текучая нанодисперсная система (наножидкость) является термин наноструктурированный материал. Таким образом, термин наножидкость входит в прототипичную модель Материал-АКО $\rightarrow$ Материал.

В некоторых источниках для обозначения родового понятия используются лексемы с очень широкой семантикой (например, система), а термин наножидкость определяется посредством указания на специфику некоторых видовых терминологических единиц. Так, «Толковый англо-русский словарь по нанотехнологии» В.В. Арсланова не дает полной дефиниции самого термина, предлагая следующую информацию:

(6) Наножидкости: Системы с равномерно распределенными нанокапельками одной несмешивающейся жидкости в другой. Такие системы известны как наноэмульсии. Равномерно распределенные твердые наночастицы в жидкости называют нанозолем или коллоидным раствором (Арсланов, с. 167). 
Словарная статья под названием «Наножидкости» на сайте RusNanoNet Российской национальной нанотехнологической сети предлагает идентичное толкование:

(7) Наножидкости (Nanofluids): Наноэмульсии (равномерно распределенные нанокапельки одной несмешивающейся жидкости в другой) наиболее известные примеры наножидкостей. Равномерно распределенные твердые наночастицы в жидкости называют нанозолем или коллоидным раствором (RusNanoNet).

Цитируемые словарные статьи содержат дефиниции терминов наноэмульсия, нанозоль, связанных с термином наножидкость отношениями $\mathrm{AKO}$ и являющихся его гипонимами. Родовидовые отношения между этими терминами актуализируются и в научных статьях, например:

(8) Классифицировать наножидкости, как и дисперсные жидкости вообще, следует по нескольким признакам. Первым является агрегатное состояние, здесь можно выделить наногазовзвеси (газ + твердые наночастицы), нанозоли (газ + жидкие наночастицы), наносуспензии (жидкость + твердые наночастицы), наноэмульсии (жидкость + жидкие наночастицы) и жидкости с нанопузырьками (Рудяк, Белкин, с. 156).

Таким образом, смежные термины наножидкость и наногазовзвесь, наножидкость и нанозоль, наножидкость и наносуспензия, наножидкость и наноэмульсия, наножидкость и жидкость с нанопузырьками также являются репрезентантами модели Материал-АКО $\rightarrow$ Материал.

Еще один смежный термин в рамках данной модели, который также включен в словарную статью «Наножидкости» и в «Толковом англо-русском словаре по нанотехнологии» В.В. Арсланова, и в RusNanoNet, - магнитная наножидкость:

(9) Дисперсная фаза магнитных наножидкостей представляет собой однодоменные магниты, равномерно распределенные в объеме дисперсной фазы (Арсланов, с. 167).

(10) Дисперсная фаза магнитных наножидкостей представляет собой однодоменные магниты, равномерно распределенные в объеме дисперсной фазы, подобные системы могут управляться магнитным полем для обеспечения герметизации механических вводов вакуумных систем при производстве полупроводников, в вакуумных печах, электронных микроскопах и других вакуумных установках (RusNanoNet).

При этом отношение АКО отражено и в структуре данного термина посредством использования в качестве основообразующего терминоэлемента его гиперонима наножидкость.

Анализ дефиниции термина наножидкость в научных статьях позволил определить, что с ним соотносятся термин ультрадисперсная система и его синоним нанодисперсная коллоидная система, но эти термины не являются прямыми гиперонимами:

(11) В соответствии с агрегатным состоянием дисперсионной среды используют различные названия нанодисперсной коллоидной системы, в т. ч. наноматериалы и наножидкости. Наножидкости представляют собой коллоидные системы (золи, устойчивые к коагуляции и седиментации), содержащие наночастицы размером около 10 нм в воде, масле, органическом растворителе с концентрацией частиц менее $1 \%$ (Большая российская энциклопедия).

Согласно Словарю Роснано, разновидность «дисперсных систем» составляют «коллоидные системы», «в которых размер частиц дисперсной фазы не превышает 1 мкм» (Словарь Роснано). В статье «Дисперсные системы» в этом словаре обнаруживаем градацию размеров, которыми должны обладать частицы в системе, чтобы она могла называться «коллоидной»: «в коллоидных системах частицы имеют размеры от 1 нм до 1 мкм (Словарь Роснано). В статье, дающей дефиницию термину «ультрадисперсный», отмечено, что «многие коллоидные системы могут быть примерами ультрадисперсных систем» (Словарь Роснано). В других источниках термин «ультрадисперсный» уточняется:

(12) К нано-(ультрадисперсным) относятся системы, в которых размер составляющих элементов (частиц, зерен, кристаллитов) менее 100 нм (Данилова и др., с. 376).

Такое уточнение свидетельствует о том, что термин коллоидная система является семантически более широким в сравнении с термином ультрадисперсная система. Поскольку размер частиц в наножидкостях составляет в пределах от 1 до 100 нм, то они первоначально включены в множество «ульт- 
М.Н. Лату, О.Ю. Гукосьяни. Прототипичные модели взаимодействия терминоединиц в терминологической сети

радисперсная система» и далее в множество «коллоидная система», в некоторых источниках понятие «наножидкость» определяется посредством термина коллоидная система:

(13) Наножидкости представляют собой коллоидные системы (золи, устойчивые к коагуляции и седиментации), содержащие наночастицы размером около 10 нм в воде, масле, органическом растворителе с концентрацией частиц менее $1 \%$ (Большая российская энциклопедия).

Поскольку наножидкость входит в множество «коллоидная система», которое не является для нее ближайшим родовым понятием, то между терминами, обозначающими эти понятия, существует отношение ISA. Взаимосвязь данных смежных терминов репрезентирует модель Материал-ISA $\rightarrow$ Вещество в связи с тем, что референты терминов $\partial и с-$ персная система и коллоидная система могут иметь естественное происхождение.

Терминологические единицы, в соответствии с Межгосударственным стандартом определяющие пять видов наноструктурных материалов: текучая нанодисперсная система (наножидкость), наноструктурированный порошок, нанокомпозиционный материал, твердая нанопена, нанопористый материaл, находятся друг с другом в отношении имплицитной оппозиции, представляя собой согипонимы (лексические единицы, имеющие общее родовое понятие), внутренняя форма которых не содержит противопоставления. Взаимосвязь обозначенных терминов репрезентирует модель Материал-Iор-Материал.

\section{Прототипичные модели с партитивными отношениями между терминами}

Из дефиниций термина наножидкость следует, что значимой для понимания специфики обозначенного им понятия является информация о составе. Это отражается в наличии у данного термина смежных терминологических единиц, связанных с ним системным отношением РО. Поскольку смежные терминологические единицы относятся к разным категориям, то они представлены в разных прототипичных моделях взаимодействия тер- минов. Так, термин наножидкость связан с термином несущая (базовая) среда, который относится к категории Вещество:

(14) Наножидкостью обычно называют двухфазную систему, состоящую из несущей среды (жидкости или газа) и наночастиц с характерными размерами от 1 до 100 нм (Белкин, с. 3).

Данная пара терминов репрезентирует прототипичную модель Материаль Вещество, которая отражает тот факт, что в состав искусственных материалов могут входить вещества естественного происхождения.

Несмотря на то, что наночастицы потенциально могут быть получены и искусственным путем, как твердые объекты они существуют в природе, потому термин наночастица относится к категории Естественный объект. Соотнесенность терминов наножидкость и наночастица репрезентирует модель МатериальРО-Естественный объект, иллюстрирующая возможность образования материала элементами естественного происхождения. Обозначенная связь между данными терминами подтверждается следующими контекстами:

(15) Суспензии на основе наночастиц твердой фазы называются наножидкостями (Ривчук и др.).

(16) Основу наножидкости составляют базовая жидкость и наночастицы какого-либо высокотеплопроводного материала (Терехов и др., 1, с. 2).

Наножидкости в качестве составляющих элементов могут содержать и углеродные нанотрубки:

(17) Вопрос о возможности баллистического механизма переноса тепла в наножидкостях, в том числе в наножидкостях на основе углеродных нанотрубок, где частицы составляют лишь малую долю, еще более сложен и в настоящее время остается открытым (Терехов и др., 1, с. 11).

(18) С другой стороны, широко исследуются и наножидкости, построенные на основе углеродных нанотрубок (Рудяк, Белкин, с. 156).

(19) В работе ... экспериментально исследовалась эффективная теплопроводность наножидкостей золото+толуол, окись алюминия+вода, окись титана+вода, окись меди+вода и углеродные нанотрубки+вода (Терехов и др., 1, с. 5).

Углеродная нанотрубка представляет собой нанообъект, полученный искусственным 
путем, в связи с чем термин углеродная нанотрубка относится к категории Инструмент. Его соотнесенность с термином наножидкость представлена моделью МатериальРОИнструмент, иллюстрирующей возможность образования материала элементами искусственного происхождения.

\section{Прототипичные модели с отношением результативности и атрибутивным отношением терминов}

Прототипичной моделью взаимодействия терминов категории Материал является модель Материал-ObjR $\rightarrow$ Материал. Она отражает отношения между терминами, обозначающими искусственные вещества, одно из которых может использоваться в качестве сырья для получения другого. В описываемой терминосети такое отношение иллюстрируют термины нанопорошок и наножидкость, обозначающие исходный наноматериал (нанопорошок), манипуляции с которым приводят к получению другого вещества (наножидкости), например:

(20) Для приготовления наножидкости нанопорошок добавляется в определенной пропорции в несущую жидкость, затем дисперсная система механически перемешивается и подвергается ультразвуковой обработке, чтобы разрушить конгломераты наночастиц (Рудяк и др., с. 76).

Поскольку нанопорошок также продукт искусственного происхождения, он относится к категории Материал.

Анализ контекстов, посвященных свойствам наножидкости, позволил установить наличие смежных терминов категории Характеристика. Термины категорий Материал и Характеристика связаны посредством системного отношения At и являются составляющими элементами прототипичной модели МатериальAt-Характеристика, иллюстрирующей наличие определенных свойств у конкретного материала. Ее репрезентируют такие пары терминов, как наножидкость и вязкость, наножидкость и теплопроводность:

(21) Эффективный коэффициент вязкости разреженных суспензий впервые был вычислен Эйнштейном, который учитывал влияние частиц на гидродинамическое поле скорости несущей жидкости и, как следствие, на тензор напряжений и коэффициент вязкости (Рудяк, Белкин, с. 167).

(22) В наножидкостях зависимость вязкости от концентрации является более сложной (Черепанов, Попов, с. 27).

(23) Интерес к изучению теплопроводности наножидкостей проявился около двух десятков лет назад и был вызван необходимостью существенно повысить теплопроводность жидкостей в микроканалах, использовавшихся для охлаждения рабочих элементов плат компьютеров, различных тепловых микроэлементов, других МЭМС (микроэлектромеханических систем) (Рудяк, Белкин, с. 170).

(24) Такие отклонения экспериментальных данных от предсказанных классическим Максвелловским уравнением, по нашему мнению, могут быть связаны с физическими механизмами увеличения теплопроводности наножидкости (Жаров и др.).

Помимо терминов вязкость и теплопроводность системным отношением атрибутивности (свойственности характеристик) с термином наножидкость связан термин реология:

(25) Любые применения наножидкостей на практике требуют систематического изучения их вязкости и реологии (Минаков и др., с. 260).

(26) Рассматриваемые в данной работе наножидкости при объемных концентрациях наночастиц выше 0.25 \% оказываются вязкопластическими, причем их реология описывается реологией степенных жидкостей (Минаков и др., с. 260).

(27) Степень отклонения реологии наножидкостей от ньютоновской растет с увеличением объемной концентрации наночастиц (Минаков и др., с. 260).

(28) Экспериментальные данные по реологии наножидкостей. Указано, что наножидкости в общем случае могут иметь как ньютоновскую, так и неньютоновскую реологию. При ньютоновской реологии базовой жидкости наножидкость может менять свою реологию с ростом концентрации наночастиц. Чаще всего реология наножидкостей может быть описана определяющими соотношениями для степенных жидкостей, хотя возможна реализация и более сложных законов, например, с предельным напряжением (Рудяк).

Заметим, что наряду с термином реология используется термин реологические свойства:

(29) Были обнаружены реологические свойства тестируемых наножидкостей (Серебрякова). 
М.Н. Лату, О.Ю.Гукосьяни.. Прототипичные модели взаимодействия терминоединиц в терминологической сети

(30) Наножидкости с высокой теплопроводностью и реологическими свойствами, по мнению ..., , также могут приводить к изменению гидродинамического трения (Терехов и др., 2, с. 175).

Представленные контексты демонстрируют атрибутивную связь между терминами наножидкость и реологические свойства (изображен на схеме (см. рисунок) как синоним термина реология).

\section{Прототипичные модели с отношением локации}

Термин наножидкость связан системным отношением Loc с термином nроцессы переноса, который относится к категории Процесс. Соотнесенность данных терминов репрезентирует модель Материал $\leftarrow \mathbf{L o c - ~}$ Процесс, поскольку процессы переноса протекают в наножидкостях:

(31) Во всех случаях ключевую роль играют процессы переноса в наножидкостях и характер их течений. Наряду с прикладным аспектом изучение процессов переноса в наножидкостях имеет и важную фундаментальную составляющую (Рудяк, Белкин, с. 157-158).

(32) Процессы переноса в наножидкостях описываются набором флуктуационно-диссипационных теорем (Рудяк, Белкин, с. 157-158).

Модель МатериальLос-Процесс выражает также связь терминов наножидкость и броуновское движением наночастий:

(33) Следует отметить ряд преимуществ применения нанофлюидов... - при хорошей агрегативной стабильности наночастиц они... находятся в жидкости в состоянии броуновского движения (Хлиева и др.).

(34) Интенсификация процесса теплоотдачи с участием нанофлюидов может объясняться рядом причин: наличием броуновского движения наночастиц (Хлиева и др.).

В рассматриваемой терминосети может быть реализовано семантическое отношение результативности $\mathrm{R}$, отражающее отношение между процессом и его результатом. Термин наножидкость категории Материал связан такими отношениями с терминами, относящимися к категории Процесс (одноступенчатый метод, двухступенчатый метод):
(35) Существующие методы изготовления наножидкостей подразделяют на одноступенчатые и двухступенчатые; Одноступенчатый метод, получивший название VEROS (Vacuum Evaporation onto a Running Oil Substrate) состоит в следующем: металл испаряется электронным пучком в вакуумной камере и здесь же оседает на покрытый маслом (базовая жидкость) вращающийся диск (Антонов и др., с. 208).

(36) При двухступенчатых методах наночастицы сначала производятся, а затем вносятся в жидкость (Антонов и др., с. 208).

(37) При одноступенчатых методах наножидкость получают в течение одного технологического цикла (Терехов и др., 1, с. 3-4).

(38) Одноступенчатый метод, получивший название VEROS (Vacuum Evaporation onto a Running Oil Substrate техника), был предложен (Akoh, 1978) (Терехов и др., 1, с. 3-4).

(39) По сравнению с одноступенчатыми методами, хорошо работающими для частиц из металлов, двухступенчатая техника предпочтительна для частиц из окислов из-за их меньшей склонности к агломерации (Терехов и др., 1, с. 3-4).

Таким образом, реализуется прототипичная модель Материал $\leftarrow \mathbf{R}-$ Процесс.

\section{Заключение}

В рамках настоящего исследования выявлены системные отношения термина наножидкость со смежными терминологическими единицами в рамках терминологии нанотехнологий. На основании полученных данных построены прототипичные модели взаимодействия терминов, раскрывающие специфику системной соотнесенности понятий изучаемой области.

Будучи сложными структурными элементами терминологической сети, данные модели демонстрируют, как именно термин наножидкость встроен в иерархическую классификацию наноструктурированных материалов, что, несомненно, найдет отражение в процессе создания экспертной системы рассматриваемой области знаний с целью ускорения процесса извлечения данных из системы, достижения интеллектуализации информационного поиска.

\section{ПРИМЕЧАНИЕ}

${ }^{1}$ Публикация выполнена в рамках реализации проекта «Разработка лингвистических принципов 


\section{РАЗВИТИЕ И ФУНКЦИОНИРОВАНИЕ РУССКОГО ЯЗЫКА}

проектирования и создание экспертной системы представления элементов научного знания на основе конструирования терминологических семантических сетей» по проектной части государственного задания Министерства образования и науки РФ на 2017-2019 гг. (№ 34.3234.2017/ПЧ).

\section{СПИСОК ЛИТЕРАТУРЫ}

Вассерман Л. И., Червинская К. Р., 2010. Извлечение знаний экспертов при проектировании экспертных систем в области медицинской психодиагностики // Биотехносфера. № 2 (8). C. $28-34$.

Гукосьянц О. Ю., Лату М. Н., 2017. Некоторые способы изучения и моделирования организации научного знания // Филология: научные исследования. № 4. С. 32-49.

Джексон П., 2001. Введение в экспертные системы. М. : Вильямс. 393 с.

Лату М. Н., 2016. Принципы построения терминологических сетей: типы вершин и отношений // Вопросы когнитивной лингвистики. Вып. 4. C. $142-149$.

Лату М. Н., Левит А. А., 2016. Изучение системности термина при помощи семантической сети // Вестник Калмыцкого института гуманитарных исследований РАН. № 2. С. 116-124.

Левит А. А., 2017. Понятийные категории, выражаемые терминами области астрофизики // Haучный диалог. № 6. С. 43-58.

Мальковский М. Г., Соловьев С. Ю., 2012. Терминологические сети // Открытые семантические технологии проектирования интеллектуальных систем (OSTIS-2012) : материалы II Междунар. науч.-техн. конф. (Минск, 1618 февраля 2012 г.) / редкол. : В. В. Голенков (отв. ред.) [и др.]. Минск : БГУИР. С. 77-82.

Chernyshenko A. G., Alimuradov O. A., 2013. Linguistic parameters of the mediation discourse // Middle East Journal of Scientific Research. Vol. 15, № 8. P. 1092-1096.

Faber P., León P., Prieto J. A., 2009. Semantic relations, dynamicity, and terminological knowledge bases // Current Issues in Language Studies. Vol. 1, iss. 1. P. 1-23.

Gillam L., Tariq M., Ahmad K., 2006. Terminology and the construction of ontology // Terminology. Vol. 11, iss. 1. P. 55-81.

Latu M. N., 2018. Some productive schemes of academic concepts relations // INTCESS 2018 : Abstracts $\&$ Proceedings $\left(5^{\text {th }}\right.$ International Conference on Education and Social Sciences (Istanbul, 57 February 2018). Turkey, Istanbul : OCERINT. P. 97-102.
Malaise V., Zweigenbaum P., Bachimont B., 2004. Detecting semantic relations between terms in definitions // CompuTerm. $3^{\mathrm{d}}$ International Workshop on Computational Terminology (Geneva, 29 ${ }^{\text {th }}$ August 2004) / ed. by S. Ananiadou, P. Zweigenbaum. Switzerland, Geneva : University of Geneva. P. 55-62.

Razduev A. V., 2018. Anthropocentric features of the scientific-technical term formation (case study of nanotechnology terms) // Espacios. Vol. 39, iss. 2. URL: http://www.revistaespacios.com/ a18v39n02/a18v39n02p21.pdf.

Steyvers M., Tenenbaum J., 2005. The large-scale structure of semantic networks: statistical analysis and a model of semantic growth // Cognitive Science. Vol. 29, iss. 1. P. 41-78.

\section{ИСТОЧНИКИ И СЛОВАРИ}

Антонов и дp. - Антонов В. Н., Агапитов Е. Б., Байкова Д. А. Перспективы применения жидкостей с наночастицами в теплоэнергетике // Актуальные проблемы современной науки, техники и образования : материалы 74-й междунар. науч.-техн. конф. : в 2 т. Магнитогорск : Магнитог. гос. техн. ун-т им. Г.И. Носова, 2016. T. 1. C. 207-210.

Арсланов - Арсланов В. В. Толковый англо-русский словарь по нанотехнологии. М. : ИФХЭ РАН, 2009. $261 \mathrm{c}$.

Белкин - Белкин А. А. Статистическая теория и моделирование процессов переноса в дисперсных жидкостях, включая наножидкости : автореф. дис. ... д-ра физ.-мат. наук. Томск, 2017. 31 с.

Большая российская энцииклопедия - Большая российская энциклопедия. URL: https://bigenc.ru/ chemistry/text/2247849 (дата обращения: 15.05.2018).

ГОСТ ISO/TS 80004-4-2016 - ГОСТ ISO/TS 800044-2016. Нанотехнологии. Часть 4. Материалы наноструктурированные. Термины и определения. Введ. 2017-07-01. М. : Стандартинформ, 2016.8 c. URL: https://standartgost.ru/ g/ГOCT_ISO/TS_80004-4-2016 (дата обращения: 27.04.2018).

Данилова и др. - Данилова Е. А., Гусев А. М., Домкин К. И. Классификация дисперсных систем и влияние размеров частиц на некоторые свойства // Труды международного симпозиума надежность и качество : в 2 т. Пенза : Пензен. гос. ун-т, 2011. Т. 2. С. 376-379.

Жаров и др. - Жаров А. В., Савинский Н. Г., Павлов А. А., Евдокимов А. Н. Экспериментальный метод измерения теплопроводности наножидкости // Фундаментальные исследо- 
вания. 2014. № 8, ч. 6. URL: https://fundamentalresearch.ru/ru/articla/view?id=34766 (дата обращения: 18.05.2018).

Иванов, Ивахнюк-Иванов А. В., Ивахнюк Г. К. Применение электрофизического метода управления процессами парообразования легковоспламеняющихся жидкостей в условиях модификации углеродными нанокомпонентами // Вестник Санкт-Петербургского университета государственной службы МЧС России. 2015. № 3. URL: https://cyberleninka.ru/article/ v/primenenie-elektrofizicheskogo-metodaupravleniya-protsessami-paroobrazovaniyalegkovosplamenyayuschihsya-zhidkostey-vusloviyah (дата обращения: 05.05.2018).

Минаков и др. - Минаков А. В., Рудяк В. Я., Гузей Д. В., Лобасов А. С. Измерение коэффициента теплоотдачи наножидкости на основе воды и частиц оксида меди // Теплофизика высоких температур. 2015. Т. 53, № 2. С. 256-263.

Наножидкости не выдерживают проверки - Наножидкости не выдерживают проверки. URL: http://www.nanonewsnet.ru/news/2007/ nanozhidkosti-ne-vyderzhivayut-proverki (дата обращения: 03.05.2018).

Нанотехнологии могут охлаждать серверные фермbl - Нанотехнологии могут охлаждать серверные фермы. URL: http://www.nanonewsnet.ru/ articles/2010/nanotekhnologii-mogut-okhlazhdatservernye-fermy (дата обращения: 05.05.2018).

Ривчук и др. - Ривчук А. А., Лобасов А. С., Минаков А. В. Повышение эффективности рекуперативных теплообменников с помощью наножидкости // Молодежь и наука : сб. материалов Х Юбилейной Всерос. науч.-техн. конф. студентов, аспирантов и молодых ученых с междунар. участием, посвящ. 80-летию образования Краснояр. края. Красноярск : Сиб. федер. ун-т, 2014. URL: http:// elib.sfu-kras.ru/handle/2311/17583 (дата обращения: 16.05.2018).

Рудяк - Рудяк В. Я. Особенности теплофизических характеристик наножидкостей. URL: http://studydoc.ru/doc/3863435/osobennostiteplofizicheskih-harakteristik-nanozhidkostej (дата обращения: 20.05.2018).

Рудяк, Белкин - Рудяк В. Я., Белкин А. А. Моделирование коэффициентов переноса наножидкостей // Наносистемы: физика, химия, математика. 2010. Т. 1, № 1. С. 156-177.

Рудяк и др. - Рудяк В. Я., Минаков А. В., Краснолуцкий С. Л. Физика и механика процессов теплообмена в течениях наножидкостей // Физическая мезомеханика. 2016. Т. 19, № 1. С. 75-83.

Рютин - Рютин С. Б. Исследование теплопереноса в перспективных теплоносителях при мощном тепловом воздействии : дис. ... канд. физ.-мат. наук. Екатеринбург, 2014. 118 с.

Серебрякова - Серебрякова М. А. Теплопроводность и вязкость наножидкостей на основе $10 \%$ раствора воды в этиленгликоле и наночастиц $\mathrm{Al}_{2} \mathrm{O}_{3}$. URL: http://www.itp.nsc.ru/ conferences/avtfg14/files/82.pdf(дата обращения: 07.05.2018).

Словарь Роснано - Словарь Роснано. URL: http:// thesaurus.rusnano.com (дата обращения: 25.04.2018).

Терехов и др., 1 - Терехов В. И., Калинина С. В., Леманов В. В. Механизм теплопереноса в наножидкостях: современное состояние проблемы (обзор). Часть 1. Синтез и свойства наножидкостей // Теплофизика и аэромеханика. 2010. № 1. С. 1-15.

Терехов и др., 2 - Терехов В. И., Калинина С. В., Леманов В. В. Механизм теплопереноса в наножидкостях: современное состояние проблемы (обзор). Часть 2. Конвективный теплообмен // Теплофизика и аэромеханика. 2010. №2. С. 173-188.

Хлиева и др. - Хлиева О. Я., Рябикин С. С., Железный В. П., Гордейчук Т. В. Экспериментальное исследование конвективного коэффициента теплоотдачи хладоносителя с добавками наночастиц $\mathrm{AL}_{2} \mathrm{O}_{3}$. URL: http://www.ie.asm.md/ assets/files/16A-64.pdf (дата обращения: 21.05.2018).

Черепанов, Попов - Черепанов И. Н., Попов В. А. Экспериментальное исследование влияния концентрации на параметры наножидкости // Вестник Пермского университета. Физика. 2017. № 2 (36). С. 26-32.

Шимчук, Геллер - Шимчук Н. А., Геллер В. 3. Влияние различных факторов на теплопроводность нанофлюидов // Восточно-европейский журнал передовых технологий. 2014. Т. 6, № 11 (72). С. 35-40.

RusNanoNet - Российская национальная нанотехнологическая сеть. Список терминов. URL: http://www.rusnanonet.ru/tesaurus/ru/17911/ (дата обращения: 25.04.2018).

\section{REFERENCES}

Vasserman L.I., Chervinskaya K.R., 2010. Extraction of Experts' Knowledge when Designing Expert Systems in the Field of Medical Psychodiagnostics. Biotekhnosfera, no. 2 (8), pp. 28-34.

Gukosyants O.Yu., Latu M.N., 2017. Some Ways of Studying and Modeling Scientific Knowledge Representation. Filologiya: nauchnye issledovaniya [Philology: Scientific Researches], no. 4, pp. 32-49. 
Jackson P. Introduction to Expert Systems. Moscow, Vilyams Publ., 2001. 393 p.

Latu M.N., 2016. Principles of Terminological Networks Construction: Types of Vertices and Arcs. Voprosy kognitivnoy lingvistiki [Issues of Cognitive Linguistics], iss. 4, pp. 142-149.

Latu M.N., Levit A.A., 2016. The Study of Systemacy of Technical Terms by Means of Semantic Network. Vestnik Kalmytskogo instituta gumanitarnykh issledovaniy RAN [Bulletin of the Kalmyk Institute for Humanities Research], no. 2, pp. 116-124.

Levit A.A., 2017. Conceptual Categories Expressed by Terms of Astrophysics. Nauchniy dialog, no. 6, pp. 43-58.

Malkovskiy M.G., Solovyev S.Yu., 2012. Terminological Networks. Otkrytye semanticheskie tekhnologii proektirovaniya intellektualnykh sistem (OSTIS-2012): materialy II Mezhdunar. nauchn.-tekhn. konf. (Minsk, 16-18 fevralya 2012 g.) [Open Semantic Technologies for Intelligent Systems (OSTIS-2012)]. Minsk, BGUIR Publ., pp. 77-82.

Chernyshenko A.G., Alimuradov O.A., 2013. Linguistic Parameters of the Mediation Discourse. Middle East Journal of Scientific Research, vol. 15, no. 8, pp. 1092-1096.

Faber P., León P., Prieto J.A., 2009. Semantic Relations, Dynamicity, and Terminological Knowledge Bases. Current Issues in Language Studies, vol. 1, iss. 1, pp. 1-23.

Gillam L., Tariq M., Ahmad K., 2006. Terminology and the Construction of Ontology. Terminology, vol. 11, iss. 1, pp. 55-81.

Latu M.N., 2018. Some Productive Schemes of Academic Concepts Relations. INTCESS 2018. Abstracts \& Proceedings ( $5^{\text {th }}$ International Conference on Education and Social Sciences (Istanbul, 5-7 February 2018). Turkey, Istanbul, OCERINT Publ., pp. 97-102.

Malaise V., Zweigenbaum P., Bachimont B., 2004. Detecting Semantic Relations Between Terms in Definitions. CompuTerm. $3^{\mathrm{d}}$ International Workshop on Computational Terminology (Geneva, 29th August 2004). Switzerland, Geneva, University of Geneva Publ., pp. 55-62.

Razduev A.V., 2018. Anthropocentric Features of the Scientific-Technical Term Formation (Case Study of Nanotechnology Terms). Espacios, vol. 39, iss. 2. URL: http://www.revistaespacios.com/ a18v39n02/a18v39n02p21.pdf

Steyvers M., Tenenbaum J., 2005. The Large-Scale Structure of Semantic Networks: Statistical Analysis and a Model of Semantic Growth. Cognitive Science, vol. 29, iss. 1, pp. 41-78.

\section{SOURSES AND DICTIONARIES}

Antonov V.N., Agapitov E.B., Baykova D.A. Perspektivy primeneniya zhidkostey $\mathrm{s}$ nanochastitsami $\mathrm{V}$ teploenergetike [The Prospects of Using Liquids with Nanoparticles in Heat-power Engineering]. Aktualnye problemy sovremennoy nauki, tekhniki i obrazovaniya: materialy 74-y mezhdunarodnoy nauchno-tekhnicheskoy konferentsii [Current Problems of Modern Science, Equipment and Education: Proceedings of the $74^{\text {th }}$ International Scientific and Technical Conference]. In 2 vols. Vol. 1. Magnitogorsk, Nosov Magnitogorsk State Technical University Publ., 2016, pp. 207-210.

Arslanov V.V. Tolkoviy anglo-russkiy slovar po nanotekhnologii [The Explanatory EnglishRussian Dictionary on Nanotechnology]. Moscow, IFKHE RAN Publ., 2009. 261 p.

Belkin A.A., Statisticheskaya teoriya i modelirovanie protsessov perenosa $v$ dispersnykh zhidkostyakh, vklyuchaya nanozhidkosti : avtoref. dis. ... d-ra fiz.-mat. nauk. [The Statistical Theory and Modeling of Transfer Processes in Disperse Liquids including Nanoliquids. Dr. phys. and math. sci. abs. diss.]. Tomsk, 2017.31 p.

Bolshaya rossiyskaya entsiklopediya [Big Russian Encyclopedia]. URL: https://bigenc.ru/ chemistry/text/2247849 (Accessed 15 May 2018).

GOST ISO/TS 80004-4-2016. Nanotekhnologii. Chast 4. Materialy nanostrukturirovannye. Terminy $i$ opredeleniya. Vved. 2017-07-01. [GOST ISO / TS 80004-4-2016. Nanotechnologies. Part 4. Nanostructured materials. Terms and definitions. Introduction 01 July 2017]. Moscow, Standartinform Publ., 2016. 8 p. URL: http:// docs.cntd.ru/document/1200141446 (Accessed 27 April 2018).

Danilova E.A., Gusev A.M., Domkin K.I. Klassifikatsiya dispersnykh sistem i vliyanie razmerov chastits na nekotorye svoystva [Classification of Disperse Systems and Influence of the Particles Size on Some Properties]. Trudy mezhdunarodnogo simpoziuma nadezhnost $i$ kachestvo. In 2 vols. Vol. 2. Penza, Penza State University Publ., 2011, pp. 376-379.

Zharov A.V., Savinskiy N.G., Pavlov A.A., Evdokimov A.N. Eksperimentalnyy metod izmereniya teploprovodnosti nanozhidkosti [Experimental Method of Measurement of Heat Conductivity of Nanoliquid]. Fundamentalnye issledovaniya [Fundamental Research], 2014, no. 8, part 6. URL: https://fundamental-research.ru/ ru/articla/view?id=34766 (Accessed 18 May2018). 
Ivanov A.V., Ivakhnyuk G.K. Primenenie elektrofizicheskogo metoda upravleniya protsessami paroobrazovaniya legkovosplamenyayushchikhsya zhidkostey $\mathrm{v}$ usloviyakh modifikatsii uglerodnymi nanokomponentami [Electrophysical Control Methods of Vaporization ofFlammable Liquids with Carbon Nanoparticles]. Vestnik Sankt-Peterburgskogo universiteta GPS MCHS Rossii, 2015, no. 3. URL: https:// cyberleninka.ru/article/v/primenenieelektrofizicheskogo-metoda-upravleniyaprotsessami-paroobrazovaniya-legkovosplamenyayuschihsya-zhidkostey-v-usloviyah (Accessed 05 May 2018).

Minakov A.V., Rudyak V.Ya., Guzey D.V., Lobasov A.S. Izmerenie koeffitsienta teplootdachi nanozhidkosti na osnove vody i chastits oksida medi [Measurement of the Heat Transfer Coefficient of a Nanofluid Based on Water and Copper Oxide Particles in a Cylindrical Channel]. Teplofizika vysokikh temperatur [High Temperature], 2015, vol. 53, no. 2, pp. 256-263.

Nanozhidkosti ne vyderzhivayut proverki [Nanoliquids don't Stand Testing]. URL: http://www. nanonewsnet.ru/news/2007/nanozhidkosti-nevyderzhivayut-proverki (Accessed 03 May 2018).

Nanotekhnologii mogut okhlazhdat servernye fermy [Nanotechnologies can Cool Server Farms]. URL: http://www.nanonewsnet.ru/articles/2010/ nanotekhnologii-mogut-okhlazhdat-servernyefermy (Accessed 05 May 2018).

Rivchuk A.A., Lobasov A.S., Minakov A.V. Povyshenie effektivnosti rekuperativnykh teploobmennikov s pomoshch'yu nanozhidkosti [Increase in Efficiency of Recuperative Heat Exchangers by Means of Nanoliquid]. Molodezh i nauka: sbornik materialov X Yubileynoy Vserossiyskoy nauchno-tekhnicheskoy konferentsii studentov, aspirantov $i$ molodykh uchenykh $s$ mezhdunarodnym uchastiem, posvyashchennoy 80-letiyu obrazovaniya Krasnoyarskogo kraya. Krasnoyarsk, Sibirskiy Federalnyy Universitet Publ., 2014. URL: http://elib.sfu-kras.ru/handle/ 2311/17583 (Accessed 16 May 2018).

Rudyak V.Ya. Osobennosti teplofizicheskikh kharakteristik nanozhidkostey [Features of Thermophysical Characteristics of Nanoliquids]. URL: http://studydoc.ru/doc/3863435/ osobennosti-teplofizicheskih-harakteristiknanozhidkostej (Accessed 20 May 2018).

Rudyak V.Ya., Belkin A.A. Modelirovanie koeffitsientov perenosa nanozhidkostey [Modeling of Nanoliquids Transfer Coefficients]. Nanosistemy: fizika, khimiya, matematika [Nanosystems: Physics, Chemistry, Mathematics], 2010, vol. 1, no. 1,pp. 156-177.
Rudyak V.Ya., Minakov A.V., Krasnolutskiy S.L. Fizika i mekhanika protsessov teploobmena $\mathrm{V}$ techeniyakh nanozhidkostey [Physics and Mechanics of Heat Exchange Processes in Nanofluid Flows]. Fizicheskaya mezomekhanika [Physical Mesomechanics Journal], 2016, vol. 19, no. 1 ,pp. $75-83$.

Ryutin S.B. Issledovanie teploperenosa v perspektivnykh teplonositelyakh pri moshchnom teplovom vozdeystvii: dis. ... kand. fiz.-mat. nauk [The Study of Heat Transfer in Prospective Heat Carriers with a Strong Heat Impact. Cand. phys. and math. sci. abs. diss.]. Ekaterinburg, 2014. 118 p.

Serebryakova M.A. Teploprovodnost $i$ vyazkost nanozhidkostey na osnove $10 \%$ rastvora vody v etilenglikole $i$ nanochastits Al2O3. [Thermal Conductivity and Viscosity of Nanoliquids on the Basis of $10 \%$ Solution of Water in Ethylene Glycol and $\mathrm{Al}_{2} \mathrm{O}_{3}$ Nanoparticles]. URL: http:// www.itp.nsc.ru/conferences/avtfg14/files/82.pdf (Accessed 07 May 2018).

Slovar Rosnano [The Dictionary of Russian Corporation of Nanotechnologies]. URL: http:// thesaurus.rusnano.com (Accessed 25 April 2018).

Terekhov V.I., Kalinina S.V., Lemanov V.V. Mekhanizm teploperenosa v nanozhidkostyakh: sovremennoe sostoyanie problemy (obzor). Chast 1. Sintez i svoystva nanozhidkostey [The Mechanism of Heat Transfer in Nanofluids: State of the Art (Review). Part 1. Synthesis and Properties of Nanofluids]. Teplofizika $i$ aeromekhanika [Thermophysics and Aeromechanics], 2010, no. 1, pp. 1-15.

Terekhov V.I., Kalinina S.V., Lemanov V.V. Mekhanizm teploperenosa v nanozhidkostyakh: sovremennoe sostoyanie problemy (obzor). Chast 2 . Konvektivnyy teploobmen [The Mechanism of Heat Transfer in Nanofluids: State of the Art (Review). Part 2. Convective Heat Transfer]. Teplofizika $i$ aeromekhanika [Thermophysics and Aeromechanics], 2010, no. 2, pp. 173-188.

Khlieva O.Ya., Ryabikin S.S., Zhelezniy V.P., Gordeychuk T.V. Eksperimentalnoe issledovanie konvektivnogo koeffitsienta teplootdachi khladonositelya s dobavkami nanochastits AL2O3 [Experimental Investigation of the Convective Heat Transfer Coefficient of Coolants with $\mathrm{AL}_{2} \mathrm{O}_{3}$ Nanoparticles Additives]. URL: http:/ /www.ie.asm.md/assets/files/16A-64.pdf (Accessed 21 May 2018).

Cherepanov I.N., Popov V.A. Eksperimentalnoe issledovanie vliyaniya kontsentratsii na parametry nanozhidkosti [Experimental Study of 


\section{РАЗВИТИЕ И ФУНКЦИОНИРОВАНИЕ РУССКОГО ЯЗЫКА}

the Influence of Concentration on the Prameters of a Nanofluid]. Vestnik Permskogo universiteta. Fizika [Bulletin of Perm University. Physics], 2017, no. 2 (36), pp. 26-32.

Shimchuk N.A., Geller V.Z. Vliyanie razlichnykh faktorov na teploprovodnost nanoflyuidov [Influence of Various Factors on the Thermal Conductivity of Nanofluids]. Vostochno- evropeyskiy zhurnal peredovykh tekhnologiy [East European Journal of Enterprise Advanced Technologeis], 2014, vol. 6, no. 11 (72), pp. 35-40. Rossiyskaya natsionalnaya nanotekhnologicheskaya set. Spisok terminov [Russian National Nanotechnological Network. List of Terms]. URL: http:/www.rusnanonet.ru/tesaurus/ru/17911/ (Accessed 25 April 2018).

\section{Information about the Authors}

Maksim N. Latu, Candidate of Sciences (Philology), Professor, Department of West European Languages and Cultures, Pyatigorsk State University, Prosp. Kalinina, 9, 357532 Pyatigorsk, Russia, laatuu@yandex.ru, https://orcid.org/0000-0002-6313-5637

Olga Yu. Gukosyants, Candidate of Sciences (Philology), Associate Professor, Department of West European Languages and Cultures, Pyatigorsk State University, Prosp. Kalinina, 9, 357532 Pyatigorsk, Russia, Gukosjants@mail.ru, https://orcid.org/0000-0001-7879-8436

\section{Информация об авторах}

Максим Николаевич Лату, кандидат филологических наук, профессор кафедры западноевропейских языков и культур, Пятигорский государственный университет, просп. Калинина, 9, 357532 г. Пятигорск, Россия, laatuu@yandex.ru, https://orcid.org/0000-0002-6313-5637

Ольга Юрьевна Гукосьянц, кандидат филологических наук, доцент кафедры западноевропейских языков и культур, Пятигорский государственный университет, просп. Калинина, 9, 357532 г. Пятигорск, Россия, Gukosjants@mail.ru, https://orcid.org/0000-0001-7879-8436 